\title{
INFLUÊNCIA DAS CONCENTRAÇÕES DE ÁCIDO SULFÚRICO NA GERMINAÇÃO IN VITRO DE Pterogyne nitens TUL. (FABACEAE)
}

\author{
Rosália Nazareth Rosa Trindade ${ }^{1}$ \\ Renolde Rodrigues ${ }^{2}$ \\ Lucas Anderson Fernandes Cordeiro ${ }^{3}$ \\ Vinícius Faúla Aguiar ${ }^{4}$ \\ Clara de Almeida Guerra ${ }^{5}$ \\ Bruno Oliveira Lafetá ${ }^{6}$
}

Resumo: O objetivo foi avaliar o efeito de diferentes concentrações de ácido sulfúrico na desinfestação, oxidação e germinação in vitro de sementes de Pterogyne nitens. O experimento foi conduzido no laboratório de Cultura de Tecidos Vegetais do IFMG. O delineamento foi inteiramente ao acaso, com quatro repetições de 12 sementes, sendo estudado o efeito de cinco concentrações de ácido sulfúrico. A avaliação do número de sementes germinadas, oxidadas e desinfestadas foi feita três vezes por semana, por 20 dias. Os dados foram submetidos à análise de variância. As maiores porcentagens de desinfestação 27,08 e $16,67 \%$ foi observado nas sementes tratadas com 25 e $100 \%$ do ácido. Os tratamentos com 75 e $100 \%$ de ácido sulfúrico não se diferenciaram e apresentaram maiores porcentagens de germinação (93,75 e 83,33\%, respectivamente) e oxidação (89,58 e 83,33\%, respectivamente). A concentração de $100 \%$ de ácido sulfúrico apresentou os melhores resultados para a desinfestação e germinação.

Palavras-chave: Pau-amendoim; Semente; Escarificação química; Cultura de tecido.

\footnotetext{
1 Departamento de Engenharia Florestal/Universidade Federal dos Vales do Jequitinhonha e Mucuri, Diamantina/MG, Brasil. E-mail: rosalia.trindade22@gmail.com.

2 Agronomia/Instituto Federal de Educação, Ciência e Tecnologia de Minas Gerais, São João Evangelista/MG, Brasil. E-mail: renolderodrigues26@gmail.com.

3 Agronomia/Instituto Federal de Educação, Ciência e Tecnologia de Minas Gerais, São João Evangelista/MG, Brasil. E-mail: lucasanderson02@hotmail.com.

4 Agronomia/Instituto Federal de Educação, Ciência e Tecnologia de Minas Gerais, São João Evangelista/MG, Brasil. E-mail: vinicius.aguiar.agr@gmail.com.

5 Departamento de Engenharia Florestal/Universidade Federal dos Vales do Jequitinhonha e Mucuri, Diamantina/MG, Brasil. E-mail: clara.ifmg.sil@hotmail.com.

6 Departamento de Engenharia Florestal/Universidade Federal dos Vales do Jequitinhonha e Mucuri, Diamantina/MG, Brasil. E-mail: bruno.lafeta@ifmg.edu.br.
} 